\title{
TRADUÇÃO, REPRESENTAÇÃO E MEMÓRIA: INTERSEÇÕES BABÉLICAS
}

\author{
Juliana Helena Gomes Leal \\ Doutoranda FALE/UFMG
}

\begin{abstract}
RESUMO
Partindo da metáfora da torre de Babel, apresentada por Jacques Derrida, na obra Torres de Babel, que contempla a ideia do "não acabamento, [da] impossibilidade de contemplar, de totalizar, de saturar, de acabar qualquer coisa”, quando discorre sobre os limites interpostos ao ato de traduzir, pretendo refletir, neste artigo, sobre o estatuto da memória e da representação como noções que contêm em si mesmas duplos antagônicos - não excludentes - (tal como a ideia de phármakon também discutida por Derrida; a de olvido, por Ricœur e a de representação, por Foucault).

PALAVRAS-CHAVE
\end{abstract}

Memória, representação, tradução

Partindo do mito da torre de Babel, que Jacques Derrida, na obra Torres de Babel, relaciona com a ideia de um "não acabamento, [da] impossibilidade de contemplar, de totalizar, de saturar, de acabar qualquer coisa”, ${ }^{1}$ quando discorre sobre o ato de traduzir, pretendo refletir, neste artigo, acerca do estatuto da memória e da representação como noções que contêm, em si mesmas, duplos antagônicos - não excludentes - tal como está contemplado no significado da palavra phármakon, também discutida por Derrida; ${ }^{2}$ a de olvido, por Ricœur; ${ }^{3}$ e a de representação, por Foucault. ${ }^{4}$

Jacques Derrida, em Torres de Babel, argumenta sobre uma "necessidade de figuração", de uma "tradução inadequada para suprir aquilo que a multiplicidade nos

\footnotetext{
${ }^{1}$ DERRIDA. Torres de Babel, p. 11-12.

2 DERRIDA. A farmácia de Platão.

${ }^{3}$ RICEUR. El olvido.

${ }^{4}$ FOUCAULT. Las meninas.
} 
interdiz”. ${ }^{5}$ Essa inadequação seria, a meu ver, a própria figuração, isto é, a exigência mesma que um texto deve enfrentar, quando diante da necessidade de representar qualquer coisa ou quando um eu se vê diante do desejo de tangenciar, ainda que levemente, os meandros da memória. A figuração ou a inadequação, entendidas a partir desse ponto de vista, ao contrário de reduzir o valor do original, do objeto a ser representado ou da memória que se quer resgatar, acrescentaria a ele(ela) um sentido que surge justamente a partir daquilo que pressupunham perder no momento desse contato, dessa aproximação.

Representação, memória e tradução seriam, desse modo, noções que se sustentam, contraditoriamente, por meio daquilo que lhes é acrescido, perpetuando-se, assim, graças ao que lhes parecia alheio, e, ao mesmo tempo, por aquilo cuja faceta se mostrava mais familiar. É nos interstícios dessas tentativas de aproximações - que quase sempre se dão a partir de afastamentos sucessivos - que o conhecimento é formado e a arte ganha impulso para a renovação. Talvez seja por essa razão que Márcio Seligmann-Silva tenha preferido usar o termo "apresentação” - segundo ele, em termos kantianos -, em lugar do termo "representação” (o imitatio), porque o primeiro é, para ele, “o único adequado para as idéias estéticas e éticas”. ${ }^{6}$ Mas se o referencial da tradução se constitui, também, por meio daquilo que lhe falta, daquilo que lhe é alheio (se não fosse assim, talvez, não falaríamos no distanciamento existente entre uma determinada coisa que se deseja representar e a representação que se consegue fazer dela, o que nos sinaliza para o caráter também não-totalizante, da configuração mesma dos objetos e das coisas), qual a razão em se discutir "um endividamento por parte do tradutor"? ${ }^{7}$ Se o termo necessidade é entendido por Derrida como impossibilidade, ${ }^{8}$ ao se referir ao ato tradutório, para que atribuir ao texto a ser traduzido, à coisa a ser representada ou ao fato a ser rememorado uma dívida, se esses termos não se constituem por meio de essencialismos unisemânticos, mas, ao contrário, por antagonismos não excludentes, tais como os pares lembrança e esquecimento, quando nos referimos à memória; visibilidade e invisibilidade, à representação e necessidade e impossibilidade, à tradução?

\footnotetext{
${ }^{5}$ DERRIDA. Torres de Babel, p. 11.

${ }^{6}$ SELIGMANN-SILVA. História, memória, literatura: o testemunho na Era das Catástofres, p. 391.

${ }^{7}$ Benjamin citado por DERRIDA. Torres de Babel, p. 27.

${ }^{8}$ DERRIDA. Torres de Babel, p. 21.
} 
Derrida parece se recusar a aceitar essencialismos que, supostamente, constituiriam as coisas quando, na obra A farmácia de Platão, ao se referir à escritura ou ao pharmákon, revela que seu valor e seu ser não existem previamente à leitura, à apreciação de um sujeito, mas que se dão por meio deste. ${ }^{9}$ Nesse sentido, por que dar crédito a uma dívida por parte do tradutor que se esforça por se aproximar do original, do escritor que batalha por representar a "realidade” ou daquele que luta por rememorar algum evento, se o que resulta desses esforços, desses movimentos empreendidos - que, inevitavelmente, acrescentam algo novo aos seus referentes - é, precisamente, o que dá sentido aos objetos primeiros de seus desejos? E “porque o phármakon não pode jamais ser simplesmente benefício", ${ }^{10}$ diz Derrida, por que a representação, a tradução, a rememoração deveriam às coisas, ao original ou ao passado uma subserviência se nem elas mesmas estão constituídas por totalizações de sentido?

Paul Ricœur, por exemplo, ao abordar o conceito olvido, problematiza sua função, entendida, quase sempre, como uma “disfunção ou distorção da memória”11 quando argumenta que: “ciertos hechos (...) refuerzan la idea paradójica de que el olvido puede estar tan estrechamente unido a la memoria que puede considerarse como una de sus condiciones", ${ }^{12}$ inclusive porque, apropriando-me das palavras de Derrida, "uma memória sem limites não seria, aliás, uma memória, mas a infinitude de uma presença a si”. 13

Michel Foucault, no capítulo "Las meninas”, da obra As palavras e as coisas, ao realizar um estudo do jogo da representação presente no quadro do pintor espanhol Velásquez, que inclui, na cena representada na tela, também o espectador que o contempla, nos chama a atenção, do mesmo modo, para um interessante jogo de visibilidade e invisibilidade que permite uma constante atualização do quadro, um "balancear imóvel”, ${ }^{14}$ feito de visibilidades invisíveis. A concepção artística dessa obra do pintor espanhol dilui, portanto, a ideia de uma representação fechada em si mesma, por permitir a inclusão de um ou mais elementos que não se encontram visíveis na tela (o rei Filipe IV e sua esposa Mariana e/ou cada um dos observadores da tela que se

\footnotetext{
${ }^{9}$ DERRIDA. A farmácia de Platão, p. 22.

${ }^{10}$ DERRIDA. A farmácia de Platão, p. 46.

${ }^{11}$ RICEEUR. El olvido, p. 555.

${ }^{12}$ RICEUUR. El olvido, p. 555.

${ }^{13}$ DERRIDA. A farmácia de Platão, p. 56.

${ }^{14}$ FOUCAULT. Las meninas, p. 14.
} 
colocar no raio de alcance do olhar do pintor, disposto à direita do quadro), mas que, muito embora, fazem parte da representação da cena como um todo.

A respeito dessa configuração dual, inerente à representação das coisas, argumenta Foucault:

(...) a relação da linguagem com a pintura é uma relação infinita. Não que a palavra seja imperfeita e esteja, em face do visível, num déficit que em vão se esforçaria por recuperar. São irredutíveis uma ao outro: por mais que se diga o que se vê, o que se vê não se aloja jamais no que se diz, e por mais que se faça ver o que se está dizendo por imagens, metáforas, comparações, o lugar onde estas resplandecem não é aquele que os olhos descortinam, mas aquele que as sucessões da sintaxe definem. ${ }^{15}$

Se Foucault admite que "o que se vê jamais se aloja no que se diz" e se acrescentamos a essa reflexão a argumentação de Derrida que versa sobre o valor que dará o rei à escrita presente no texto Phármakon, em A farmácia de Platão - julgamento de valor este que fará parte da constituição da escrita - como contemplar a possibilidade ou viabilidade da existência de uma representação, segundo Foucault que "pode se dar como pura representação”? ${ }^{16}$ Como uma representação dessa natureza seria possível? O adjetivo puro contemplaria a existência de uma representação livre de interferências externas ou de outra que fosse, simplesmente e tão somente, uma representação naturalmente propensa a contaminações e a interferências várias?

Mas, diz Derrida:

(...) sob pretexto de suprir a memória, a escritura faz esquecer ainda mais; longe de ampliar o saber, ela o reduz. Ela não responde à necessidade da memória, aponta para outro lado, não consolida a mnéme, somente a hupómnésis. Ela age, pois, como todo phármakon. ${ }^{17}$

Concordo com essa configuração dialética da memória - tal como o phármakon -, mas suspeito, e muito, desse reducionismo que a escritura imporia ao saber. Não encontraria o saber sua possibilidade de existência justamente nas localidades a partir das quais ele pareceria estar sendo reduzido? Por que não pensar que, reduzindo-se, ele, fatalmente, ${ }^{18}$ se ampliaria? Essa não seria a matéria mesma da constituição do phármakon, quando

\footnotetext{
${ }^{15}$ FOUCAULT. Las meninas, p. 12. (grifo meu).

${ }^{16}$ FOUCAULT. Las meninas, p. 21.

${ }^{17}$ DERRIDA. A farmácia de Platão, p. 47.

${ }^{18}$ Uso esse advérbio para contemplar tanto a ideia de fatalismo (no sentido pejorativo) quanto de algo a que é inevitável resistir.
} 
entendido, por Platão, ao mesmo tempo como veneno e remédio? Reduções não podem ser vistas como ampliações, se se parte do entendimento de uma dualidade intrínseca à constituição das coisas, dos eventos, tal como a constituição de olvido, apresentada por Ricœur, ${ }^{19}$ por exemplo? Por que, então, haver frustração por uma impossibilidade de atingir o original, de uma impossibilidade de representar uma coisa ou um fato vivido, se esses só têm sentido na medida em que há um outro que o (re)significa (que tenta roçar sua face fluída e ambígua), dando-lhe, assim, justamente condições para a sua permanência?

Por essa razão, no movimento mesmo de uma tentativa de restituição do sentido original do texto traduzido ou da apreensão da faceta real da coisa representada ou, ainda, da captura da dimensão do fato vivido, não há, por parte do tradutor, do escritor ou do sujeito que lembra uma dívida a ser quitada (como admite Derrida, ao se referir ao argumento de Benjamin, ${ }^{20}$ simplesmente porque há, segundo Derrida - e aqui é o ponto que mais me interessa -, uma dimensão "performativa dos enunciados"21 que viabiliza, justamente por essa “impossibilidade" constituinte, a construção do conhecimento durante o ato tradutório, durante o exercício mnemônico, bem como durante a representação de uma "realidade" dada, ou melhor, representada ou, ainda, segundo Seligmann-Silva, apresentada.

Ainda a propósito dos dois significados contemplados para o termo “representação", afirma Barthes: "No sentido corrente, aquele com que se relaciona a obra clássica, a representação designa uma cópia, uma ilusão, uma figura analógica, um produto semelhante; mas, no sentido etimológico, a re-presentação é a volta daquilo que se apresentou”. ${ }^{22}$ Os dois sentidos do termo - o clássico e o etimológico - vislumbram, ambos, um retorno redentor de uma coisa que não teria razão para se repetir indefinidamente na significação de outrem, já que perderia, nesse esforço, o privilégio da originalidade. Para Derrida, no entanto, o original pede “um complemento”, porque, "na origem, ele [o original] não estava lá sem falta, pleno, completo, total, idêntico a si". 23

\footnotetext{
${ }^{19}$ RICEEUR. El olvido.

${ }^{20}$ DERRIDA. Torres de Babel, p. 33.

${ }^{21}$ DERRIDA. Torres de Babel, p. 34.

${ }^{22}$ BARTHES. O óbvio e o obtuso, p. 206.

${ }^{23}$ DERRIDA. Torres de Babel, p. 47.
} 
Mais uma vez, insisto na ideia, agora com o reforço de Derrida, no questionamento da ideia de dívida, visto que, por qual razão o tradutor deveria se sentir impotente ou endividado ou, ainda, ameaçado pela incapacidade de uma apreensão total de algo que nem sequer nunca pôde estar lá? Se se concorda que o original é uma "tradução" do real, uma das tantas maneiras de se representar a realidade, como exigir dele - do tradutor - o domínio estrito desse original, se tanto o original quanto a tradução são representações? O primeiro, de uma realidade, e o segundo, outra representação?

E se considerarmos factível o endividamento do original em relação a si mesmo, já que a maneira por meio da qual representa a realidade nunca será a realidade em si, porque sempre se contradirá, se afastará, realizando, portanto, uma recriação, na tentativa de aproximação daquilo que pretendia representar, por que deveria o tradutor carregar, sozinho, o peso de uma suposta dívida, se o original é, antes de tudo, uma das inúmeras possibilidades (interpretações, versões) de se representar determinada realidade?

Representar, relembrar ou traduzir, ao contrário do que se poderia supor, se fundaria, ironicamente, na morte do seu alvo para lhes dar vida, já que, por exemplo, parece ser consensual, admitir que traduções oferecem uma sobrevida significativa aos textos que tomaram como ponto de partida. Nesse sentido, qual seria a produtividade de se perpetuar ecos amorfos e unisemânticos de um mesmíssimo evento, coisa ou texto, se esse exercício, essa tarefa é, simplesmente, impossível, tal como crer em uma torre de Babel absoluta, harmônica, completa, total? A dimensão performática do relato seria, desse modo, uma espécie de fantasma - mas um fantasma produtivo -, que vivificaria seu referencial por perceber nele (e em si mesmo) um caráter de incompletude. Não uma incompletude tomada como deficiência, mas como lugar da criação.

Quando Derrida fala sobre uma sobrevida (crescimento e engrandecimento) do texto ou, ainda, sobre a "expansão simbólica" ${ }^{24}$ que a tradução lhe possibilita, penso no empobrecimento da discussão sobre débitos e dívidas em relação a algo que nos escapa sempre, quando tentamos representá-lo, traduzi-lo ou rememorá-lo. Por essa razão, é que falo sobre interseções babélicas entre esses termos, em razão dessa impossibilidade inescapável de totalização, de saturação. Dificuldades que, ao contrário do que

\footnotetext{
${ }^{24}$ DERRIDA. Torres de Babel, p. 46, 49.
} 
poderíamos supor, fornecem amplas possibilidades, fortalecedoras e infinitas, para o ato criativo e para a arte.

\section{ABSTRACT}

The starting point of this work is Jacques Derrida's assumption- taken from his book The Towers of Babel (2002) - that the concept of memory from the Tower of Babel implies the idea of "non-ending, [of the] impossibility of contemplating, totalizing, saturating, and ending anything”, when he broaches the limits that are inherent to the translation act. Based on it, I reflect on the status of memory and representation as notions that have inside themselves the double antagonic and non-excludent entities carried by the notions of phármakon, discussed by Derrida, of olvido, by Ricœur , and representation, by Foucault.

\section{KEYWORDS}

Memory, representation, translation

\section{REFERÊNCIAS}

BARTHES, Roland. O óbvio e o obtuso. Trad. Léa Novaes. Rio de Janeiro: Nova Fronteira, 1990.

DERRIDA, Jacques. A farmácia de Platão. Trad. Rogério da Costa. São Paulo: Iluminuras, 1991.

DERRIDA, Jacques. Torres de Babel. Trad. Junia Barreto. Belo Horizonte: Ed. UFMG, 2002.

FOUCAULT, Michel. Las meninas. In: . As palavras e as coisas: uma arqueologia das ciências humanas. Trad. Salma Tannus Muchail. São Paulo: Martins Fontes, 1999. p. 3-21.

RICEEUR, Paul. El olvido. In: . La memoria, la historia, el olvido. Buenos Aires: Fondo de Cultura Económica, 2000. p. 539-591.

SELIGMANN-SILVA, Márcio (Org.). História, memória, literatura: o testemunho na Era das Catástofres. Campinas: Ed. Unicamp, 2003. 